\title{
Basic life support training for single rescuers efficiently augments their willingness to make early emergency calls with no available help: a cross-over questionnaire survey
}

Keiko Hirose ${ }^{1}$, Miki Enami ${ }^{1}$, Hiroki Matsubara', Takahisa Kamikura' ${ }^{1}$ Yutaka Takei ${ }^{2}$ and Hideo Inaba ${ }^{1 *}$

\begin{abstract}
Background: The aim of this study was to investigate effects of basic life support (BLS) training on willingness of single rescuers to make emergency calls during out-of-hospital cardiac arrests (OHCAs) with no available help from others.

Methods: A cross-over questionnaire survey was conducted with two questionnaires. Questionnaires were administered before and after two BLS courses in fire departments. One questionnaire included two scenarios which simulate OHCAs occurring in situations where help from other rescuers is available (Scenario-M) and not available (Scenario-S). The conventional BLS course was designed for multiple rescuers (Course-M), and the other was designed for single rescuers (Course-S).

Results: Of 2,312 respondents, 2,218 (95.9\%) answered all questions and were included in the analysis. Although both Course-M and Course-S significantly augmented willingness to make early emergency calls not only in Scenario-M but also in Scenario-S, the willingness for Scenario-M after training course was significantly higher in respondents of Course-S than in those of Course-M (odds ratio 1.706, 95\% confidential interval 1.301-2.237). Multiple logistic regression analysis for Scenario-M disclosed that post training (adjusted odds ratio 11.6, 95\% confidence interval 7.84-18.0), age (0.99, 0.98-0.99), male gender $(1.77,1.39-2.24)$, prior BLS experience of at least three times $(1.46,1.25-2.59)$, and time passed since most recent training during 3 years or less $(1.80,1.25-2.59)$ were independently associated with willingness to make early emergency calls and that type of BLS course was not independently associated with willingness. Therefore, both Course-M and Course-S similarly augmented willingness in Scenario-M. However, in multiple logistic regression analyses for Scenario-S, Course-S was independently associated with willingness to make early emergency calls in Scenario-S $(1.26,1.00-1.57)$, indicating that Course-S more efficiently augmented willingness. Moreover, post training $(2.30,1.86-2.83)$ and male gender $(1.26,1.02-1.57)$ were other independent factors associated with willingness in Scenario-S.
\end{abstract}

Conclusions: BLS courses designed for single rescuers with no help available from others are likely to augment willingness to make early emergency calls more efficiently than conventional BLS courses designed for multiple rescuers.

Keywords: Emergency call, Basic life support, Willingness, Bystander, Training course

\footnotetext{
* Correspondence: hidinaba@med.kanazawa-u.ac.jp

1 Department of Emergency Medical Science, Kanazawa University Graduate

School of Medicine, 13-1 Takaramachi, Kanazawa 920-8641, Japan

Full list of author information is available at the end of the article
} 


\section{Background}

Survival after out-of-hospital cardiac arrests (OHCAs) depends on adherence to stages of the 'chain of survival'. These include immediate recognition of cardiac arrest and activation of the emergency response system, early cardiopulmonary resuscitation (CPR), rapid defibrillation, effective advanced life support and integrated post-cardiac arrest care [1-3]. In particular, appropriate and prompt performance of the first three stages is essential for survival after OHCA [4-6]. In fact, accumulating evidence indicates that long delays in making emergency calls are associated with poorer OHCA outcomes [7-9]. These delays may reduce the beneficial effects of dispatcherassisted CPR (DA-CPR) [10-13] because bystanders more frequently initiate CPR according to DA-CPR than on their own initiative [14].

A majority of OHCAs occur at home [15-17] and are relatively isolated from the emergency medical service (EMS) system. Therefore, multiple rescuers are rarely present [18] and the recognition of cardiac arrest, and the activation of EMS systems is frequently delayed $[9,19]$. Public education on the importance of making early emergency calls may be effective in reducing this delay [20]. However, flowcharts in BLS guidelines and textbooks are basically designed for OHCAs witnessed by multiple rescuers $[1-3,21]$. Therefore, the situations for which most BLS courses provide training are ideally those where help from others are easily available.

This study investigated the effects of BLS courses for single rescuers on their willingness to make emergency calls as lone bystanders. Because BLS courses for citizens are most frequently held in fire departments in Japan [22], we designed and conducted this study in co-operation with fire departments in our community.

\section{Methods}

Data were collected in accordance with the national ethics guidelines for epidemiological surveys [23]. The study was approved by the review board of Kanazawa University Graduate School of Medicine (reference number: 924) (Table 1).
We conducted this investigation in co-operation with eight fire departments of the Ishikawa Prefecture. All eight fire departments were divided into two groups according to their location (three in central and four in non-central regions). The study period was from 1 July 2010 to 30 June 2011 and was divided into four terms. In each term, participants in BLS courses held by each fire department were assigned in a cross-over manner to one of four study groups which were classified on the basis of types of course design and questionnaire scenarios: $\mathrm{M}-\mathrm{M} / \mathrm{S}, \mathrm{M}-\mathrm{S} / \mathrm{M}, \mathrm{S}-\mathrm{M} / \mathrm{S}$, and S-S/M (Table 2).

One type of BLS course was conventional and was designed for multiple rescuers (Course-M), whereas the other was designed for single rescuers (Course-S). In course-M, participants were given a BLS instruction predominantly in a public location where they can send someone to place an emergency call and another to find and bring an AED. In course-S, participants were principally trained to act as single rescuers in a place where no help from others is initially available; they were instructed to place an emergency call on their own with a mobile or cordless phone and leave the victim only when there is no other option. In both course, all participants were similarly educated for CPR and AED use. All instructors involved in this study were fire department staff and were qualified to instruct on BLS. They were informed of the study design and were given a standard instruction manual. Two types of questionnaire were administered to participants in different orders before and after the BLS instruction course. One questionnaire included two scenarios (Scenario-M1 and Scenario-M2) which simulate OHCA cases wherein help from others is available. The other included scenarios (Scenario-S1 and ScenarioS2) wherein no help is available or the respondent is a lone rescuer. These two types of questionnaires were administered in different orders before and after the BLS instruction course. For respondent background, the questionnaire included age, gender, residential area, occupation, prior BLS training experience, and the time since the most recent course.

Table 1 Study groups and design

\begin{tabular}{lcccc}
\hline & \multicolumn{2}{c}{ Study groups } \\
\cline { 2 - 5 } Type of instruction & \multicolumn{1}{c}{ M-M/S } & M-S/M & S-M/S & S-S/M \\
\hline Type of scenarios in questionnaires & \multicolumn{2}{c}{ For multiple rescuers } & & For single rescuer \\
Pre-training questionnaires & Scenario-M & Scenario-S & Scenario-M & Scenario-S \\
Post-training questionnaires & Scenario-S & Scenario-M & Scenario-S & Scenario-M \\
Study terms & & & & \\
In central regions & & & $2011.1 .1-2011.3 .31$ & $2011.4 .1-2011.6 .30$ \\
In non-central regions & $2010.7 .1-2010.9 .30$ & $2010.10 .1-2010.12 .31$ & $2010.7 .1-2010.9 .30$ & $2010.10 .1-2010.12 .31$ \\
\hline
\end{tabular}

Scenario-M, in cases with multiple rescuers; Scenario-S, in cases with a single rescuer. 
Table 2 Questionnaire and choice

\begin{tabular}{|c|c|c|c|}
\hline Scenarios-M & Choices & Scenarios-S & Choices \\
\hline Scenario-M1: & (a) Call 119 by yourself* & Scenario-S1: & $\begin{array}{l}\text { (a) Call } 119 \text { with your } \\
\text { phone* }^{*}\end{array}$ \\
\hline \multirow{7}{*}{$\begin{array}{l}\text { In the afternoon on Sunday, you found } \\
\text { an unknown woman collapsed in a } \\
\text { station. She was unresponsive and } \\
\text { was breathing abnormally. Passersby } \\
\text { crowded around you and the woman. } \\
\text { What do you do first? }\end{array}$} & $\begin{array}{l}\text { (b) Ask one of the passersby } \\
\text { to call } 119 \text { and start chest } \\
\text { compressions* }\end{array}$ & \multirow{7}{*}{$\begin{array}{l}\text { A } 65 \text {-year-old man collapsed in front } \\
\text { of you on an array in your residential } \\
\text { area. He is unresponsive. You are not } \\
\text { able to judge whether he is breathing } \\
\text { or not. Nobody is around you. You } \\
\text { have a cellular phone. What do you } \\
\text { do first? }\end{array}$} & $\begin{array}{l}\text { (b) Call your reliable friend } \\
\text { or relative }\end{array}$ \\
\hline & $\begin{array}{l}\text { (c) Inquire a reliable person } \\
\text { what you should do or } \\
\text { discuss with others } \\
\text { regarding what to do }\end{array}$ & & $\begin{array}{l}\text { (c) Go back home and } \\
\text { report the event to your } \\
\text { family }\end{array}$ \\
\hline & $\begin{array}{l}\text { (d) Call } 119 \text { only when } \\
\text { you are requested }\end{array}$ & & $\begin{array}{l}\text { (d) Go to the nearest } \\
\text { residency and ask for } \\
\text { help }\end{array}$ \\
\hline & $\begin{array}{l}\text { (e) Look for a station } \\
\text { staff first }\end{array}$ & & $\begin{array}{l}\text { (e) Keep on checking if he } \\
\text { is breathing }\end{array}$ \\
\hline & $\begin{array}{l}\text { (f) Keep on observing the } \\
\text { woman }\end{array}$ & & (f) Call police \\
\hline & (g) Leave the scene & & $\begin{array}{l}\text { (g) Start chest compressions } \\
\text { and wait for someone }\end{array}$ \\
\hline & (h) Other & & (h) Other \\
\hline Scenario-M2: & (a) Call 119 by yourself* & Scenario-S2 & (a) Call $119^{*}$ \\
\hline \multirow{6}{*}{$\begin{array}{l}\text { You and many relatives were at a } \\
\text { relative's home for a Buddhist memorial } \\
\text { event. One of your family members } \\
\text { complained of sudden chest pain and } \\
\text { collapsed. He or she became } \\
\text { unresponsive. One of your relative } \\
\text { reported that she or he is not breathing } \\
\text { and appears to be in cardiac arrest. } \\
\text { What do you do first? }\end{array}$} & $\begin{array}{l}\text { (b) Ask one of your relatives to } \\
\text { call } 119 \text { and start chest } \\
\text { compressions* }\end{array}$ & \multirow{6}{*}{$\begin{array}{l}\text { When you are alone at home, your } \\
\text { uncle visited you. When you talked } \\
\text { with him, he complained of sudden } \\
\text { chest pain and collapsed. He is } \\
\text { unresponsive and breathing } \\
\text { abnormally. What do you do? }\end{array}$} & $\begin{array}{l}\text { (b) Call your reliable friend } \\
\text { or relative }\end{array}$ \\
\hline & $\begin{array}{l}\text { (c) Discuss with others } \\
\text { regarding what to do }\end{array}$ & & (c) Call his family \\
\hline & $\begin{array}{l}\text { (d) Transport him or her to a } \\
\text { medical office or hospital }\end{array}$ & & $\begin{array}{l}\text { (d) Call a medical office or } \\
\text { hospital }\end{array}$ \\
\hline & $\begin{array}{l}\text { (e) Keep on observing him } \\
\text { or her }\end{array}$ & & $\begin{array}{l}\text { (e) Transport him to a } \\
\text { medical office or hospital }\end{array}$ \\
\hline & \multirow[t]{2}{*}{ (f) Other } & & (f) Keep on observing \\
\hline & & & (g) Start chest compressions \\
\hline
\end{tabular}

*Desirable action(s).

\section{Data analysis}

Data analyses were performed using JMP ver. 7 for Windows (SAS Institute). The effects of the BLS course type on the willingness to make early emergency calls were analyzed using univariate analysis, and the chisquare test was applied with and without Pearson's correction. The Kruskal-Wallis test was used for non-parametric comparisons. We used multiple regression models to confirm the effects of the BLS course type and to elucidate the factors associated with willingness to make early emergency calls. In all analyses, $p<0.05$ indicated statistical significance. If reported, unadjusted and adjusted odds ratios (ORs) have been predominantly presented in tables.

\section{Results}

\section{Number of respondents}

Of 2,312 respondents, 2,218 answered all questions and were included in analyses. No significant differences were observed in the ratio of respondents analyzed to those unanalyzed among the four study terms or between the two types of course or questionnaires (Table 3).

No significant differences were observed with regard to prior BLS experience among the four groups. However, significant differences were observed with regard to age, gender, residential area, occupation and time passed since most recent course between the four respondent groups. Particularly, a large difference was observed with regard to residential area, with the majority of respondents from the central region in Group M-M/S and those from rural areas in the other three groups (Figure 1).

Effects of Course-M and Course-S on willingness to make early emergency calls are individually presented in Scenario-M (left panel) and Scenario-S (right panel). There was a small but significant differences in willingness between Course-M and Course-S in Questionnaire Scenario-M provided before the training courses ( $p=$ 0.022 ). However, there was a larger and significant difference in willingness in Scenario-S after the training courses $(p<0.001)$. The willingness to make early 
Table 3 Comparisons of backgrounds among the four respondent groups

\begin{tabular}{|c|c|c|c|c|c|c|}
\hline & & \multicolumn{4}{|c|}{ Group of respondents } & \multirow[t]{4}{*}{$p$ value } \\
\hline & & \multicolumn{2}{|c|}{$\begin{array}{c}\text { Common instructions for } \\
\text { multiple rescuers } \\
N=885\end{array}$} & \multicolumn{2}{|c|}{$\begin{array}{l}\text { Specialized instruction for } \\
\text { single rescuer } \\
N=1,333\end{array}$} & \\
\hline & & $M-M / S$ & $M-S / M$ & S-M/S & $S-S / M$ & \\
\hline & & $N=609$ & $N=276$ & $N=832$ & $N=501$ & \\
\hline Age, Median & & $41(33-52)$ & $45(36-52)$ & $42(30-54)$ & $40(31-52)^{*}$ & $p=0.007$ \\
\hline \multirow[t]{2}{*}{ Gender, \% ( $(M)$} & Male & $34 \%(210)$ & $66 \%(182)$ & $52 \%(431)^{*}$ & $50 \%(249)^{*}$ & $p<0.0001$ \\
\hline & Female & $66 \%(399)$ & $34 \%(94)$ & $48 \%(401)^{*}$ & $50 \%(252)^{*}$ & \\
\hline \multirow[t]{3}{*}{ Residential area, \% ( $N$ ) } & Central & $85 \%(520)$ & $37 \%(101)$ & $20 \%(170)^{*}$ & $36 \%(179)$ & $p<0.0001$ \\
\hline & Rural & $14 \%(84)$ & $61 \%(168)$ & $78 \%(646)^{*}$ & $62 \%(311)$ & \\
\hline & Other & $1 \%(5)$ & $3 \%(7)$ & $2 \%(16)^{*}$ & $2 \%(11)$ & \\
\hline \multirow[t]{2}{*}{ Occupation, \% (N) } & Unemployed & $37 \%(228)$ & $37 \%(103)$ & $24 \%(199)^{*}$ & $35 \%(175)$ & $p<0.0001$ \\
\hline & Employed & $63 \%(381)$ & $63 \%(173)$ & $76 \%(633)^{*}$ & $65 \%(326)$ & \\
\hline \multirow[t]{4}{*}{ Prior BLS training experience, $\%(N)$} & None & $26 \%(159)$ & $32 \%(87)$ & $25 \%(210)$ & $27 \%(137)$ & $p=0.659$ \\
\hline & One time & $34 \%(207)$ & $30 \%(87)$ & $32 \%(269)$ & $32 \%(162)$ & \\
\hline & Two times & $20 \%(120)$ & $18 \%(49)$ & $22 \%(185)$ & $22 \%(106)$ & \\
\hline & Three times or more & $20 \%(123)$ & $21 \%(57)$ & $20 \%(168)$ & $19 \%(96)$ & \\
\hline \multirow[t]{2}{*}{ Time from most recent course } & 3 years or less & $54 \%(244 / 450)$ & $69 \%(131 / 190)$ & $66 \%(413 / 626)^{*}$ & $60 \%(218 / 364)^{*}$ & $p=0.0004$ \\
\hline & More than 3 years & $46 \%(206 / 450)$ & $31 \%(59 / 190)$ & $34 \%(213 / 626)^{*}$ & $40 \%(146 / 364)^{*}$ & \\
\hline
\end{tabular}

*Significantly different from the corresponding group receiving common instructions for multiple rescuers $(p<0.05)$; Group S-M/S vs. Group M-M/S, Group S-S/M vs. Group M-S/M.

emergency calls significantly increased after both types of course; from $68.8 \%$ to $98.1 \%$ in Course $\mathrm{M}$, from $74.3 \%$ to $95.8 \%(p<0.01$, shown by asterisks in Figure 1$)$ (Table 4).

We assessed respondent willingness to make early emergency calls as desirable choices in both questionnaire scenarios (Scenario-M and Scenario-S). We judged that respondents had willingness when they selected desirable action(s) in all of each two questionnaire scenarios. Univariate analyses revealed that willingness was significantly augmented by Course-S, which was specialized for single rescuers (unadjusted $\mathrm{OR}=1.32$ ), the post-training questionnaire (unadjusted $\mathrm{OR}=11.3$ ), younger age $(p<0.005)$, male gender (unadjusted $\mathrm{OR}=1.99$ ), employment status (unadjusted $\mathrm{OR}=1.27$ ), region other than central area (unadjusted $\mathrm{OR}=1.45$ ), prior $\mathrm{BLS}$ training experience $(p=0.002)$ and the time passed since the most recent training course $(p=0.001)$. However, multiple logistic regression analysis revealed that post-training (adjusted $\mathrm{OR}=11.6$ ), younger age (unit $\mathrm{OR}$ for age $=0.99$ ), male gender (adjusted $\mathrm{OR}=1.77$ ), prior BLS training experience of three times or more (adjusted $\mathrm{OR}=1.46$, no experience as reference) and time from most recent training course being 3 years or less (adjusted $\mathrm{OR}=1.80$ ) were significantly associated with willingness of Scenario$\mathrm{M}$ questionnaire respondents to make early emergency calls. On the other hand, the type of instruction was not an independent factor (Table 4).
Compared with the Scenario-M questionnaire, univariate analysis disclosed fewer factors related to willingness in the Scenario-S questionnaire. Willingness was significantly augmented by course-S, which was specialized for single rescuers (unadjusted $\mathrm{OR}=1.29$ ), the post-training questionnaire (unadjusted $\mathrm{OR}=2.13$ ), regions other than the central area (unadjusted $\mathrm{OR}=1.24$ ) and employment status (unadjusted $\mathrm{OR}=1.27$ ). However, prior BLS training experience did not significantly influence willingness. Multiple logistic regression analysis of responses to the Scenario-S questionnaire revealed that post-training (adjusted OR = 2.30), training Course-S (adjusted OR = 1.26) and male gender (adjusted $\mathrm{OR}=1.26$ ) were significantly associated with willingness to make early emergency calls.

\section{Discussion}

Delay of emergency calls is a preventable human factor which is associated with poor OHCA outcomes [7,8,18]. A majority of previous reports regarding education and public awareness of BLS investigate the effects of BLS education on citizens' awareness and willingness to perform bystander CPR [24-26] and the quality of CPR [27-29]. Therefore, to the best of our knowledge, this cross-over questionnaire survey is the first to assess the effects of BLS training on attitudes toward making early emergency calls and to compare two types of BLS training course that are classified by the number of rescuers present. 


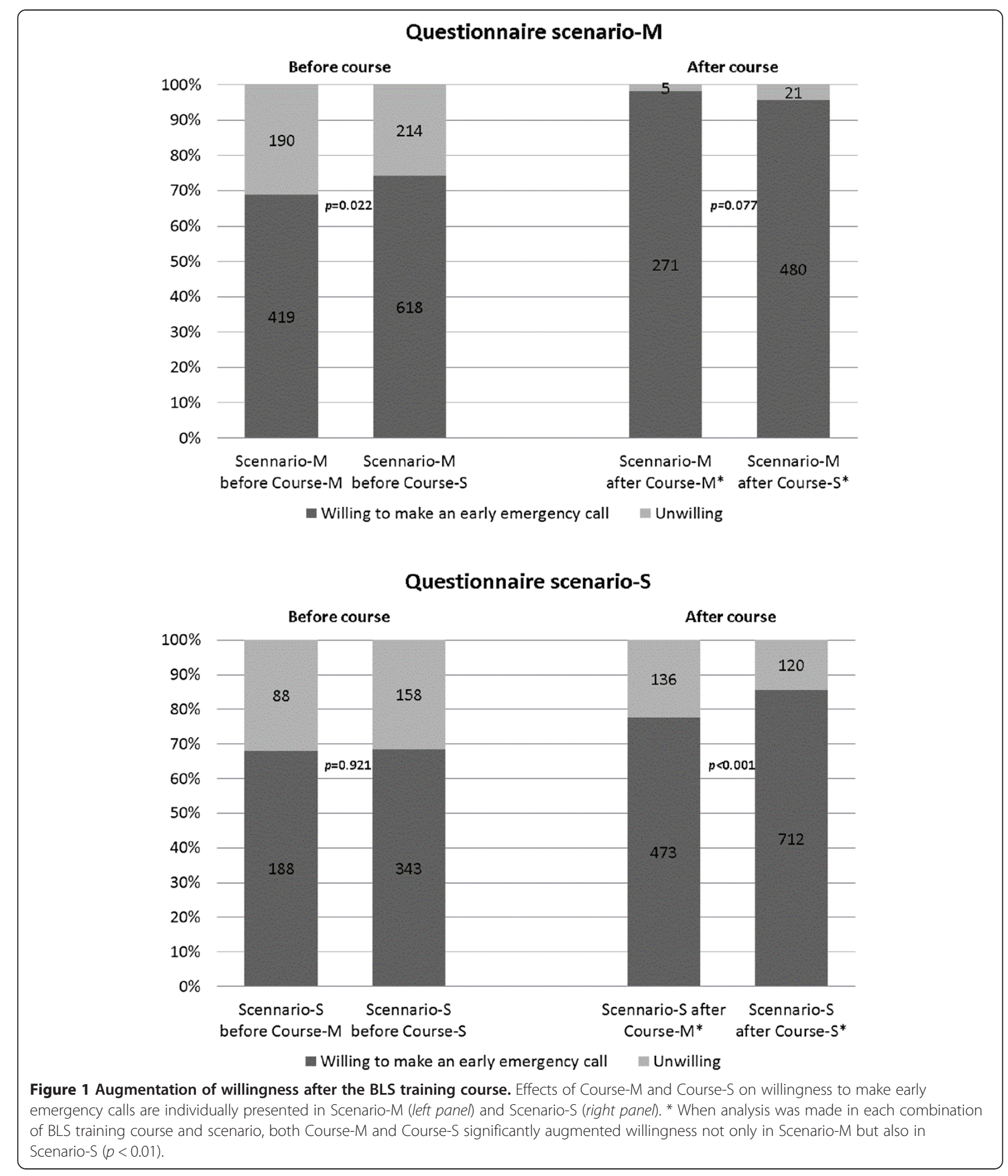

We analyzed factors associated with willingness to make early emergency calls by comparing responses to scenarios wherein help from others is easily available or multiple rescuers are present (Scenario-M questionnaire) with scenarios wherein help is unavailable (Scenario-S questionnaire). In univariate analysis shown in Figure 1, the willingness for Scenario-S questionnaire after training course was significantly higher in participants of Course-S than in those of Course-M (odds ratio 1.706, 95\% confidential interval 1.301-2.237), suggesting that Course-S 
Table 4 Univariate analysis followed by multiple logistic regression analysis

\begin{tabular}{|c|c|c|c|c|c|c|c|}
\hline \multirow[t]{3}{*}{ Factors } & & \multicolumn{6}{|c|}{ Type of questionnaire scenarios } \\
\hline & & \multicolumn{3}{|c|}{ Scenario-M providing if-cases with multiple rescuers } & \multicolumn{3}{|c|}{ Scenario-S providing if-cases with a single rescuer } \\
\hline & & $\begin{array}{l}\text { Willing to make an early } \\
\text { emergency call, \% (N) }\end{array}$ & $\begin{array}{c}p \text { or odds ratio } \\
(95 \% \mathrm{Cl}) \text { by univariate } \\
\text { analysis }\end{array}$ & $\begin{array}{l}\text { Adjusted odds ratio } \\
\text { by multiple logistic } \\
\text { regression analysis }\end{array}$ & $\begin{array}{l}\text { Willing to make an early } \\
\text { emergency call, } \%(N)\end{array}$ & $\begin{array}{c}p \text { or odds ratio } \\
(95 \% \mathrm{Cl}) \text { by univariate } \\
\text { analysis }\end{array}$ & $\begin{array}{l}\text { Adjusted odds ratio } \\
\text { by multiple logistic } \\
\text { regression analysis }\end{array}$ \\
\hline \multirow{2}{*}{$\begin{array}{l}\text { Timing for } \\
\text { questionnaire }\end{array}$} & Pre-training & $72 \%(1,037 / 1,441)$ & Reference & Reference & $68 \%(531 / 777)$ & Reference & Reference \\
\hline & Post-training & $97 \%(751 / 777)$ & $11.3(7.49-16.9)$ & $11.6(7.84-18.0)$ & $82 \%(1,185 / 1,441)$ & $2.13(1.75-2.63)$ & $2.30(1.86-2.83)$ \\
\hline \multirow[t]{2}{*}{$\begin{array}{l}\text { Type of instruction } \\
\text { course }\end{array}$} & $\begin{array}{l}\text { Course-M } \\
\text { (multiple } \\
\text { rescuers) }\end{array}$ & $78 \%(690 / 885)$ & Reference & Reference & $75 \%(661 / 885)$ & Reference & Reference \\
\hline & $\begin{array}{l}\text { Course-S (single } \\
\text { rescuer) }\end{array}$ & $82 \%(1,098 / 1,333)$ & $1.32(1.07-1.63)$ & $1.11(0.83-1.49)$ & $80 \%(1,055 / 1,333)$ & $1.29(1.05-1.57)$ & $1.26(1.00-1.57)$ \\
\hline \multirow{2}{*}{$\begin{array}{l}\text { Age, years, median } \\
(25 \%-75 \%)\end{array}$} & Unwilling & $44(35-54)$ & $p=0.005$ & $0.99(0.98-0.99)$ & $44(35-54)$ & $p=0.400$ & $1.00(0.99-1.00)$ \\
\hline & Willing & $41(32-52)$ & & & 41 (32-52) & & \\
\hline \multirow[t]{2}{*}{ Gender } & Female & $76 \%(866 / 1,146)$ & Reference & Reference & $76 \%(868-1,146)$ & Reference & Reference \\
\hline & Male & $86 \%(922 / 1,072)$ & $1.99(1.60-2.48)$ & $1.77(1.39-2.24)$ & $79 \%(848-1,072)$ & $1.21(0.99-1.48)$ & $1.26(1.02-1.57)$ \\
\hline \multirow{2}{*}{$\begin{array}{l}\text { Residential area, \% } \\
\text { (N) }\end{array}$} & Central & $77 \%$ (970/750) & Reference & Reference & $75 \%$ (730/970) & Reference & Reference \\
\hline & Others & $83 \%(1,038 / 1,248)$ & $1.45(1.17-1.79)$ & $1.25(0.93-1.67)$ & $79 \%(986 / 1,248)$ & $1.24(1.01-1.51)$ & $1.20(0.95-1.50)$ \\
\hline \multirow[t]{2}{*}{ Occupation } & Unemployed & $78 \%$ (550/705) & Reference & Reference & $75 \%(525 / 705)$ & Reference & Reference \\
\hline & Employed & $82 \%(1,238 / 1,513)$ & $1.27(1.02-1.58)$ & $1.22(0.95-1.57)$ & $79 \%(1,191 / 1513)$ & $1.27(1.03-1.56)$ & $1.09(0.87-1.37)$ \\
\hline \multirow{4}{*}{$\begin{array}{l}\text { Prior BLS training } \\
\text { experience }\end{array}$} & None & $76 \%$ (450/593) & $p=0.002$ & Reference & $77 \%(454 / 593)$ & $p=0.461$ & Reference \\
\hline & One time & $80 \%(579 / 721)$ & & $1.17(0.80-1.73)$ & $77 \%$ (556/721) & & $1.02(0.72-1.46)$ \\
\hline & Two times & $83 \%(382 / 460)$ & & $1.32(0.89-1.96)$ & $80 \%(368 / 460)$ & & $1.10(0.77-1.58)$ \\
\hline & $\begin{array}{l}\text { Three times or } \\
\text { more }\end{array}$ & $85 \%$ (377/444) & & $1.46(1.25-2.59)$ & $76 \%(338 / 444)$ & & $0.65(0.42-1.02)$ \\
\hline \multirow{3}{*}{$\begin{array}{l}\text { Duration from most } \\
\text { recent course }\end{array}$} & None & $76 \%(450 / 593)$ & $p=0.001$ & Reference & 77\% (454/593) & $p=0.008$ & Reference \\
\hline & 3 years or less & $85 \%(852 / 1,003)$ & & $1.80(1.25-2.59)$ & $80 \%(804 / 1,003)$ & & $1.30(0.94-1.79)$ \\
\hline & $\begin{array}{l}\text { More than } \\
3 \text { years }\end{array}$ & $78 \%(486 / 622)$ & & $1.04(0.72-1.49)$ & $74 \%(458 / 622)$ & & $0.86(0.62-1.19)$ \\
\hline
\end{tabular}


more efficiently augmented willingness than Course-M. Multiple logistic regression analyses of Scenario-M questionnaire responses indicated that while post-course respondents were associated with willingness, BLS course types (Course-M or Course-S) were not, suggesting that both types of BLS training course potentially augment willingness to make emergency calls in situations where multiple rescuers were present. Moreover, prior BLS training course experience within 3 years was an independent factor. In contrast, multiple logistic regression analysis of responses to the Scenario-S questionnaire revealed that post-course respondents and BLS single rescuer Course-S were independent factors associated with willingness and that prior BLS training experience was not. These results indicate that the standard BLS training course for multiple rescuers does not augment willingness to make early emergency calls when the respondent is a single rescuer. Furthermore, other independent factors associated with willingness to make early emergency calls were younger age, male gender, and employment status.

Most OHCAs occur in homes [30,31] at relatively isolated locations from the emergency medical service system, where emergency calls are frequently delayed $[9,19]$ and multiple rescuers are rarely present [18,30]. Elderly family members have the highest probability of being a victim or a bystander of at-home OHCAs $[9,30]$, and their cardiac arrests are most frequently witnessed or recognized by spouses and daughters [32,33]. The present study and our previous large questionnaire surveys [34,35] have indicated that elderly and female citizens were more reluctant to place early emergency calls, presumably because of emotional stress [36,37] and the large gender gap in Japan [38]. When these bystanders witness and recognize cardiac arrests as single bystanders or rescuers, high emotional stress leads to placement of the first call to reliable family members, relatives, friends or general practitioners $[9,34,35]$. Further, bystanders more frequently initiate CPR in compliance with DA-CPR than on their own initiative [10-13]. Therefore, during the training course-S for single rescuers, instructors emphasized the importance of making early emergency calls to get an advice from the dispatcher for resuscitation, although availability of DACPR was known to all participants in both training courses. It is likely that the BLS training course designed for single rescuers should be applied for elderly and female participants whose daily life is spent at home.

DA-CPR has been reported to increase the incidence of bystander CPR and is expected to improve the outcomes for individuals who experience OHCAs [14]. Strong recommendations for DA-CPR have been made by the International Liaison Committee on Resuscitation in their 2010 Consensus [39] as well as in a scientific statement from the American Heart Association [40]. However, the benefits of DA-CPR for OHCA outcomes are diminished by delay of emergency calls, which consequently delays bystander CPR. In addition to emphasis on early emergency calls in all BLS training courses, application of BLS training for single rescuers may diminish the delay in placing an emergency call.

This study had several limitations. Two BLS courses (Course-M and Course-S) were performed in a crossover manner in eight fire departments of the Ishikawa Prefecture. Multiple logistic regression analyses revealed that residential areas or locations of fire departments were not independent factors associated with willingness to make early emergency calls (Table 4). However, we did not evaluate the quality of BLS instructions. Moreover, although all instructors involved in this study were qualified staff adhering to standard instruction manuals, the quality of instruction may have affected the results of this study. Approximately half of the respondents were female. A majority of respondents were middle aged, were employed and had previous BLS training experience. Therefore, the results of this study may not reflect the willingness of elderly females, who are the most likely witnesses of cardiac arrests. Because of limitations of time, the questionnaire in this study was only designed to assess willingness to make early emergency calls. The willingness to perform other BLS actions, including CPR and use of automated external defibrillators, were not evaluated. The effects of two types of BLS training were evaluated by comparing answers to questionnaires administered before the BLS course with those administered immediately after the BLS course. Therefore, the duration of willingness to make early emergency calls remains unknown.

\section{Conclusions}

In contrast with the conventional BLS course for multiple rescuers, the BLS course for single rescuers is likely to efficiently augment willingness to make early emergency calls when participants are single rescuers of OHCA patients. In addition to emphasis on early emergency calls in all BLS training courses, application of BLS training for single rescuers may diminish the delay in placing an emergency call.

\section{Competing interests}

The authors declare that they have no competing interests.

\section{Authors' contributions}

$\mathrm{HI}$ conceived and designed the study. $\mathrm{KH}, \mathrm{ME}, \mathrm{HM}, \mathrm{TK}$, and $\mathrm{HI}$ cleaned, analyzed, and interpreted the data. KH, YT, and HI drafted the manuscript, and all authors contributed substantially to its revision. HI provided

administrative, technical and material support. $\mathrm{KH}$ and $\mathrm{HI}$ made a decision to submit the manuscript for publication. $\mathrm{KH}$ and ME take responsibility for integrity of the data and accuracy of the data analysis. All authors read and approved the final manuscript.

\section{Acknowledgements}

We thank the eight fire departments of the Ishikawa Prefecture for their co-operation in conducting this study. 


\section{Author details}

'Department of Emergency Medical Science, Kanazawa University Graduate School of Medicine, 13-1 Takaramachi, Kanazawa 920-8641, Japan. ${ }^{2}$ Department of Medical Science and Technology, Hiroshima International University, Hiroshima, Japan.

Received: 28 November 2013 Accepted: 27 March 2014

Published: 24 April 2014

\section{References}

1. Travers AH, Rea TD, Bobrow BJ, Edelson DP, Berg RA, Sayre MR, Berg MD, Chameides L, O'Connor RE, Swor RA: Part 4: CPR overview: 2010 American Heart Association guidelines for cardiopulmonary resuscitation and emergency cardiovascular care. Circulation 2010, 122(18 Supple 3):S676-S684.

2. Cummins RO, Ornato JP, Thies WH, Pepe PE, Billi JE, Seidel J: Improving survival from sudden cardiac arrest: the "chain of survival" concept. A statement for health professionals from the Advanced Cardiac Life Support Subcommittee and the Emergency Cardiac Care Committee, American Heart Association. Circulation 1991, 83:1832-1847.

3. Koster RW, Baubin MA, Bossaert LL, Caballero A, Cassan P, Castrén M, Granja C, Handley AJ, Monsieurs KG, Perkins GD, Raffay V, Sandroni C: European resuscitation council guidelines for resuscitation 2010 section 2 . Adult basic life support and use of automated external defibrillators. Resuscitation 2010, 81:1277-1292.

4. Hollenberg J, Herlitz J, Lindqvist J, Riva G, Bohm K, Rosenqvist M, Svensson $L$ : Improved survival after out-of-hospital cardiac arrest is associated with an increase in proportion of emergency crew-witnessed cases and bystander cardiopulmonary resuscitation. Circulation 2008, 118:389-396.

5. Garza AG, Gratton MC, Salomone JA, Lindholm D, McElroy J, Archer R: Improved patient survival using a modified resuscitation protocol for out-of-hospital cardiac arrest. Circulation 2009, 119:2597-2605.

6. Stiell IG, Wells GA, Field B, Spaite DW, Nesbitt LP, De Maio VJ, Nichol G, Cousineau D, Blackburn J, Munkley D, Luinstra-Toohey L, Campeau T, Dagnone E, Lyver M, Ontario Prehospital Advanced Life Support Study Group: Advanced cardiac life support in out-of-hospital cardiac arrest. N Engl J Med 2004, 351:647-656.

7. Herlitz J, Engdahl J, Svensson L, Young M, Angquist KA, Holmberg S: A short delay from out of hospital cardiac arrest to call for ambulance increases survival. Eur Heart J 2003, 24:1750-1755.

8. Swor RA, Compton S, Domeier R, Harmon N, Chu K: Delay prior to calling 9-1-1 is associated with increased mortality after out-of-hospital cardiac arrest. Prehosp Emerg Care 2008, 12:333-338.

9. Takei $Y$, Inaba H, Yachida T, Enami M, Goto Y, Ohta K: Analysis of reasons for emergency call delays in Japan in relation to location: high incidence of correctable causes and the impact of delays on patient outcomes. Resuscitation 2010, 81:1492-1498.

10. Carter WB, Eisenberg MS, Hallstrom AP, Schaeffer S: Development and implementation of emergency CPR instruction via telephone. Ann Emerg Med 1984, 13:695-700.

11. O'Nwill JF, Deakin CD: Evaluation of telephone CPR advice for adult cardiac arrest patient. Resuscitation 2007, 74:63-67.

12. Bohm K, Vaillancourt C, Charette ML, Dunford J, Castrén M: In patients with out-of cardiac arrest, dose the provision of dispatch cardiopulmonary resuscitation instruction as opposed to no instructions improve outcome: a systematic review of the literature. Resuscitation 2011, 82:1490-1495.

13. Bohm K, Rosenqvist M, Hollenberg J, Biber B, Engerström L, Svensson L: Dispatcher-assisted telephone-guided cardiopulmonary resuscitation: an underused lifesaving systems. Eur J Emerg Med 2007, 14:256-259.

14. Tanaka Y, Taniguchi J, Wato Y, Yoshida Y, Inaba H: The continuous quality improvement project for telephone-assisted instruction of cardiopulmonary resuscitation increased the incidence of bystander CPR and improved the outcomes of out-of-hospital cardiac arrests. Resuscitation 2012, 83:1235-1241.

15. Swor RA, Jackson RE, Compton S, Domeier R, Zalenski R, Honeycutt L, Kuhn GJ, Frederiksen S, Pascual RG: Cardiac arrest in private locations: different strategies are needed to improve outcome. Resuscitation 2003 58:171-176.

16. Eisenberg MS, Mengert TJ: Cardiac resuscitation. N Engl J Med 2001, 344:1304-1313.

17. Holmberg M, Holmberg S, Herlitz J: Swedish cardiac arrest registry. Factors modifying the effect of bystander cardiopulmonary resuscitation on survival in out-of-hospital cardiac arrest patients in Sweden. Eur Heart $J$ 2001, 22:511-519.

18. Nishi T, Maeda T, Takase K, Kamikura T, Tanaka Y, Inaba H: Does the number of rescuers affect the survival rate from out-of-hospital cardiac arrests? Two or more rescuers are not always better than one. Resuscitation 2012, 81:1492-1498.

19. Breckwoldt J, Schloesser S, Arntz HR: Perceptions of collapse and assessment of cardiac arrest by bystanders of out-of-hospital cardiac arrest (OOHCA). Resuscitation 2009, 80:1108-1113.

20. Berg RA, Hemphill R, Abella BS, Aufderheide TP, Cave DM, Hazinski MF, Lerner EB, Rea TD, Sayre MR, Swor RA: Part 5: Adult basic life support: 2010 American Heart Association guidelines for cardiopulmonary resuscitation and emergency cardiovascular care. Circulation 2010, 122:S685-S705.

21. JRC Guidelines based on 2010 Consensus on Science with Treatment Recommendations: [http://jrc.umin.ac.jp]

22. Fire and Disaster Management Agency: [http://www.fdma.go.jp/html/intro/ form/kyuu.html]

23. Ministry of Health, Labour and Welfare in Japan: [http://www.mhlw.go.jp/ general/seido/kousei/i-kenkyu/index.html]

24. Cho GC, Sohn YD, Kang KH, Lee WW, Lim KS, Kim W, Oh BJ, Choi DH, Yeom SR, Lim H: The effect of basic life support education on laypersons' willingness in performing bystander hands only cardiopulmonary resuscitation. Resuscitation 2010, 81:691-694.

25. Kanstad BK, Nilsen SA, Fredriksen K: CPR knowledge and attitude to performing bystander CPR among secondary school students in Norway. Resuscitation 2011, 82:1053-1059.

26. Lee MJ, Hwang SO, Cha KC, Cho GC, Yang HJ, Rho TH: Influence of nationwide policy on citizens' awareness and willingness to perform bystander cardiopulmonary resuscitation. Resuscitation 2013, 84:889-894.

27. Woollard M, Whitfield R, Newcombe RG, Colquhoun M, Vetter $N$, Chamberlain D: Optimal refresher training intervals for AED and CPR skills: a randomised controlled trial. Resuscitation 2006, 71:237-247.

28. Riegel B, Nafziger SD, McBurnie MA, Powell J, Ledingham R, Sehra R, Mango $L$, Henry MC: PAD trial investigators. How well are cardiopulmonary resuscitation and automated external defibrillator skills retained over time? Results from the public access defibrillation (PAD) trial. Acad Emerg Med 2006, 13:254-263.

29. Dorph E, Wik L, Steen PA: Dispatcher-assisted cardiopulmonary resuscitation. An evaluation of efficacy amongst elderly. Resuscitation 2003, 56:265-273.

30. Engdahl J, Holmberg M, Karlson BW, Luepker R, Herlitz J: The epidemiology of out-of-hospital 'sudden' cardiac arrest. Resuscitation 2002, 52:235-245.

31. Folke F, Gislason GH, Lippert FK, Nielsen SL, Weeke P, Hansen ML, Fosbøl EL, Andersen SS, Rasmussen S, Schramm TK, Køber L, Torp-Pedersen C: Differences between out-of-hospital cardiac arrest in residential and public locations and implications for public-access defibrillation. Circulation 2010, 122:623-630

32. Holmberg M, Holmberg S, Herlitz J: Effect of bystander cardiopulmonary resuscitation in out-of-hospital cardiac arrest patients in Sweden. Resuscitation 2000, 1:59-70

33. Ann-Britt T, Ella D, Johan H, Asa AB: Spouses' experiences of a cardiac arrest at home: an interview study. Eur J Cardiovasc Nurs 2010, 9:161-167.

34. Enami M, Takei Y, Inaba H, Yachida T, Ohta K, Maeda T, Goto Y: Differential effects of ageing and previous training experience on attitude towards basic life support. Resuscitation 2011, 82:577-583.

35. Enami M, Takei Y, Goto Y, Ohta K, Inaba H: The effects of the new CPR guideline on attitude toward basic life support in Japan. Resuscitation 2010, 81:562-567.

36. Swor R, Khan I, Domeier R, Honeycutt L, Chu K, Compton S: CPR training and CPR performance: do CPR-trained bystanders perform CPR? Acad Emerg Med 2006, 6:596-601.

37. Riegel B, Mosesso VN, Birnbaum A, Bosken L, Evans LM, Feeny D, Holohan J, Jones CD, Peberdy MA, Powell J: PAD Investigators. Stress reactions and perceived difficulties of lay responders to a medical emergency. Resuscitation 2006, 70:98-106.

38. Hausmann R, Tyson LD, Zahidi S: The Global Gender gap Report. Geneva. Switzerland: World Economic Forum. Cologny; 2012. http://www.weforum. org/issues/global-gender-gap.

39. Hazinski MF, Nolan JP, Billi JE, Böttiger BW, Bossaert L, de Caen AR, Deakin CD, Drajer S, Eigel B, Hickey RW, Jacobs I, Kleinman ME, Kloeck W, Koster 
RW, Lim SH, Mancini ME, Montgomery WH, Morley PT, Morrison L, Nadkarni VM, O'Connor RE, Okada K, Perlman JM, Sayre MR, Shuster M, Soar J, Sunde $\mathrm{K}$, Travers AH, Wyllie J, Zideman D: International consensus on cardiopulmonary resuscitation and emergency cardiovascular care science with treatment recommendations. Circulation 2010, 2010(122):S250-S275.

40. Lerner EB, Rea TD, Bobrow BJ, Acker JE 3rd, Berg RA, Brooks SC, Cone DC, Gay M, Gent LM, Mears G, Nadkarni VM, O'Connor RE, Potts J, Sayre MR, Swor RA, Travers AH: Emergency medical service dispatch cardiopulmonary resuscitation prearrival instructions to improve survival from out-of-hospital cardiac arrest: a scientific statement from the American Heart Association. Circulation 2012, 125:648-655.

doi:10.1186/2052-0492-2-28

Cite this article as: Hirose et al:: Basic life support training for single rescuers efficiently augments their willingness to make early emergency calls with no available help: a cross-over questionnaire survey. Journal of Intensive Care 2014 2:28.

\section{Submit your next manuscript to BioMed Central and take full advantage of:}

- Convenient online submission

- Thorough peer review

- No space constraints or color figure charges

- Immediate publication on acceptance

- Inclusion in PubMed, CAS, Scopus and Google Scholar

- Research which is freely available for redistribution 